\title{
Morinda citrifolia Linn Leaf Extract Possesses Antioxidant Activities and Reduces Nociceptive Behavior and Leukocyte Migration
}

\author{
Mairim Russo Serafini, Rodrigo Correia Santos, Adriana Gibara Guimarães, \\ João Paulo Almeida dos Santos, ${ }^{1}$ Alan Diego da Conceicão Santos, ${ }^{2}$ Izabel Almeida Alves, ${ }^{3}$ \\ Daniel Pens Gelain, ${ }^{4}$ Paulo Cesar de Lima Nogueira, ${ }^{2}$ Lucindo José Quintans-Júnior, \\ Leonardo Rigoldi Bonjardim, and Adriano Antunes de Souza Araújo ${ }^{1}$ \\ Departments of ${ }^{1}$ Physiology and ${ }^{2}$ Chemistry, Federal University of Sergipe (UFS), São Cristóvão, Sergipe, Brazil. \\ ${ }^{3}$ Department of Microbiology and Parasitology, Laboratory of Mycological Research, \\ Federal University of Santa Maria (UFSM), Santa Moria, Rio Grande do Sul, Brazil. \\ ${ }^{4}$ Department of Biochemistry, Center for Studies on Oxidative Stress, \\ Federal University of Rio Grande do Sul (UFRGS), Porto Alegre, Rio Grande do Sul, Brazil.
}

\begin{abstract}
Herbal drugs have been used since ancient times to treat a wide range of diseases. Morinda citrifolia Linn (popularly known as "Noni") has been used in folk medicine by Polynesians for over 2,000 years. It is reported to have a broad range of therapeutic effects, including effects against headache, fever, arthritis, gingivitis, respiratory disorders, infections, tuberculosis, and diabetes. The aim of this study was to investigate the antioxidant, anti-inflammatory, antinociceptive, and antibacterial properties of the aqueous extract from $M$. citrifolia leaves (AEMC). Antioxidant activity was observed against lipid peroxidation, nitric oxide, and hydroxyl radicals. The antinociceptive effect of AEMC was observed in the acetic acid-induced writhing test at the higher dose. Moreover, AEMC significantly reduced the leukocyte migration in doses of 200 and $400 \mathrm{mg} / \mathrm{kg}$ and showed mild antibacterial activity. Together, the results suggest that properties of $M$. citrifolia leaf extract should be explored further in order to achieve newer tools for managing painful and inflammation conditions, including those related to oxidant states.
\end{abstract}

KEY WORDS: • anti-inflammatory activity • antinociceptive activity $\bullet$ antioxidant activity $\bullet$ Morinda citrifolia

\section{INTRODUCTION}

$M$ ORINDA CITRIFOLIA LINN, POPULARLY known as "noni," has been used in traditional Polynesian medicine for over 2,000 years. M. citrifolia (Rubiaceae) is native from southeast Asia to Australia and is cultivated in Polynesia, India, the Caribbean region, and central and northern South America. ${ }^{1,2}$ Cultures native to these regions favored using $M$. citrifolia for treating major diseases and used it for nourishment in times of famine. Noni fruit has been recognized by cultures as an excellent source of nutrition. ${ }^{3}$ Noni leaves have been consumed as a vegetable by many cultural groups. For this reason, it is included in the World Health Organization's and Food and Agriculture Organization's food composition tables for East Asia and the Islands of the Pacific. ${ }^{4}$

About 160 phytochemical compounds in the noni plant have already been identified, and the major secondary metabolites are phenolic compounds, organic acids, and

Manuscript received 25 September 2010. Revision accepted 25 November 2010.

Address correspondence to: Adriano Antunes de Souza Araujo, Departamento de Fisiologia, Curso de Farmácia - UFS Adress, Av. Marechal Rondom SN, CEP 49100-000 São Cristóvão - SE, Brazil, E-mail: adriasa2001@yahoo.com.br alkaloids. ${ }^{5}$ Phenolic compounds are examples of herbal compounds with widely reported antioxidant and antiinflammatory properties.

Whereas noni juice and fruit have been well characterized chemically and pharmacologically, ${ }^{1-3}$ few data are available regarding the properties of $M$. citrifolia leaves. Despite the lack of experimental data on potential therapeutic properties, the use of noni for different purposes is still widespread in many parts of the world. However, infusions prepared with the aerial parts (stems and leaves) of noni are used in folk medicine in northeast Brazil to treat painful conditions and as a sedative. Thus, the aim of the present study was to evaluate the antioxidant, antibacterial, antinociceptive, and anti-inflammatory properties of aqueous extracts from $M$. citrifolia leaves (AEMC).

\section{MATERIAL AND METHODS}

\section{Samples}

M. citrifolia leaves were collected in São Cristóvão, Sergipe, Brazil [10¹8'20.7"(S); 36'39'7.2"(W)]. Herbarium voucher specimens (registry number 13503) were prepared and deposited at the Department of Biology of the Federal 
University of Sergipe. The AEMC was prepared by boiling in distilled water (7.5\%; w/v) for 15 minutes; the solvent evaporated under reduced pressure and lyophilized.

\section{Phytochemical screening}

To detect the presence of various chemical constituents in AEMC, phytochemical screening was performed according to the method described by Matos. ${ }^{6}$ The extract was qualitatively analyzed for the presence of phenols, condensed tannins, alkaloids, volatile coumarins, flavonoids, saponins, and triterpenes. This analysis was conducted by observing colorimetric variation after the addition of specific reagents.

\section{Total phenolic content}

The total phenolic content was assayed by using the FolinCiocalteu reagent, following a slightly modified version of Singleton and colleagues' method. ${ }^{7}$ The AEMC $(100 \mathrm{mg})$ was diluted to $100 \mathrm{~mL}$ of water. An aliquot $(100 \mu \mathrm{L})$ of AEMC was added to $6 \mathrm{~mL}$ of deionized water and $500 \mu \mathrm{L}$ of the Folin-Ciocalteu reagent. The mixture was shaken for 1 minute. After addition of $2 \mathrm{~mL}$ of $15 \% \mathrm{Na}_{2} \mathrm{CO}_{3}$ solution, the mixture was shaken for 0.5 minute. The solution was then diluted with deionized water to a final volume of $10 \mathrm{~mL}$. After incubation for 120 minutes at $23^{\circ} \mathrm{C}$, the total phenolic content was determined by using a spectrophotometer at $750 \mathrm{~nm}$. Gallic acid was used as the standard, and total phenolic content was expressed as gallic acid equivalents $(\mathrm{g} / \mathrm{kg}$ of AEMC) through the calibration curve with gallic acid. The calibration curve range was $50-500 \mathrm{mg} / \mathrm{mL}\left(\mathrm{R}^{2}=0.998\right)$.

\section{High-performance liquid chromatography-photodiode- array detection analysis}

The high-performance liquid chromatography (HPLC) analyses were performed on a liquid chromatograph (Prominence, Shimadzu, Kyoto, Japan) that was equipped with a vacuum degasser (DGU-20A3), autosampler (SIL-10A), 2 high-pressure pumps (LC-6A), and a photodiode-array detector (DAD) system (SIL-10A) coupled with a CBM 20A interface. Data were collected by using LC Solution software (Shimazdu). Analysis was performed on the analytical C18 Luna column $(250 \mathrm{~mm} \times 4.6 \mathrm{~mm}$ interior diameter; 5$\mu \mathrm{m}$ particle diameter; Phenomenex, Torrance, California, USA) under the following conditions: flow rate $1.0 \mathrm{~mL} /$ minute and injection volume of $25 \mu \mathrm{L}$, with mobile phase consisting of water and acetonitrile. The gradient elution for samples was as follows: 5\%-50\% (acetonitrile) in $30 \mathrm{~min}-$ utes, $50 \%-100 \%$ (acetonitrile) in 5 minutes, $100 \%$ (acetonitrile) in 3 minutes. The DAD was set at $254 \mathrm{~nm}$ for acquiring chromatograms, and ultraviolet spectra were recorded between 190 and $800 \mathrm{~nm}$. Identification was based on co-injections of the reference compounds and comparisons of absorption spectra.

\section{In vitro experiments: antioxidant activity}

Thiobarbituric acid test. We used the thiobarbituric acid reactive species (TBARS) assay to quantify lipid peroxidation and an adapted TBARS method to measure the antioxidant capacity of AEMC, with egg yolk homogenate used as the lipid-rich substrate. ${ }^{8-10}$ Briefly, egg yolk was homogenized $(1 \% \mathrm{w} / \mathrm{v})$ in $20 \mathrm{mM}$ phosphate buffer $(\mathrm{pH}$, 7.4), and $1 \mathrm{~mL}$ of homogenate was sonicated. Lipid peroxidation was induced by addition of $0.1 \mathrm{~mL}$ of $2,2^{\prime}$-azobis (2-amidinopropane) dihydrochloride (AAPH) solution $(0.12 \mathrm{M})$. Reactions were carried out for 30 minutes at $37^{\circ} \mathrm{C}$. After cooling, AEMC $(0.5 \mathrm{~mL})$ was centrifuged with $0.5 \mathrm{~mL}$ of trichloroacetic acid (15\%) at $1200 \mathrm{~g}$ for 10 minutes. An aliquot of $0.5 \mathrm{~mL}$ from supernatant was mixed with $0.5 \mathrm{~mL}$ thiobarbituric acid $(0.67 \%)$ and was heated at $95^{\circ} \mathrm{C}$ for 30 minutes. After cooling, the absorbance of the samples was measured by using a spectrophotometer at $532 \mathrm{~nm}$. The results are expressed as percentage of TBARS formed by AAPH alone (induced control).

Nitric oxide-scavenging assay. Nitric oxide was generated from sodium nitroprusside and measured by using the Griess reaction. Sodium nitroprusside in aqueous solution at physiologic $\mathrm{pH}$ spontaneously generates nitric oxide, which interacts with oxygen to produce nitric ions that can be estimated by using the Griess reagent. Scavengers of nitric oxide compete with oxygen, thereby reducing production of nitric ions. Sodium nitroprusside $(5 \mathrm{mM})$ in phosphatebuffered saline was mixed with $3.0 \mathrm{~mL}$ of different concentrations $(1,10,100 \mu \mathrm{g} / \mathrm{mL}$ and $1 \mathrm{mg} / \mathrm{mL})$ of AEMC and incubated at $25^{\circ} \mathrm{C}$ for 60 minutes. The samples were added to Griess reagent ( $1 \%$ sulfanilamide, $2 \% \mathrm{H}_{3} \mathrm{PO} 4$, and $0.1 \%$ napthylethylenediamine dihydrochloride). The absorbance of the chromophore formed during the diazotization of nitrite with sulfanilamide and subsequent coupling with napthylethylenediamine was measured at $546 \mathrm{~nm} .{ }^{11}$

Hydroxyl radical-scavenging assay. Hydroxyl radicals were generated by a Fenton system $\left(\mathrm{FeSO}_{2}-\mathrm{H}_{2} \mathrm{O}_{2}\right)$. When exposed to hydroxyl radicals, the sugar deoxyribose is degraded to malonaldehyde, which generates a pink chromogen on heating with thiobarbituric acid at low $\mathrm{pH}$. The method for determining the scavenging on hydroxyl radicals was performed according to a previously described procedure. $^{12}$

\section{In vitro experiments: antibacterial activity}

Microdilution assays. Microorganisms were obtained from the American Type Culture Collection and were available in the Laboratory of Mycological Research at the Federal University of Santa Maria, Brazil.

The microdilution method was used for antibacterial activity tests, as recommended by the National Committee for Clinical Laboratory Standards. ${ }^{13}$ Media were placed into each of 96 wells of the microplates. AEMC solutions at 256 and $512 \mathrm{mg} / \mathrm{mL}$ were added into the first rows of the microplates, and 2-fold dilutions of the compounds (256$0.06 \mathrm{mg} / \mathrm{mL}$ ) were made by dispensing the solutions to the remaining wells. Ten-microliter culture suspensions were inoculated into all the wells. The sealed microplates were incubated at $35^{\circ} \mathrm{C}$ for 24 hours in a humid chamber. The 
lowest concentration of the extracts that completely inhibit macroscopic growth was determined, and minimum inhibitory concentrations (MICs) were reported. Antimicrobial activity of the AEMC was tested against gram-positive and gram-negative bacteria.

To classify the activity of the extract, the following criteria were observed: MIC up to $100 \mu \mathrm{g} / \mathrm{mL}$ is considered to indicate good antimicrobial activity; MIC from 100 to $500 \mu \mathrm{g} / \mathrm{mL}$ is considered to represent moderate activity; and MIC greater than $1,000 \mu \mathrm{g} / \mathrm{mL}$ is considered to show inactivity. ${ }^{14-16}$

\section{In vivo experiments}

Animals. Male Swiss mice $(25-30 \mathrm{~g})$ were kept in a controlled-temperature room (mean temperature \pm standard deviation, $21^{\circ} \mathrm{C} \pm 2^{\circ} \mathrm{C}$ ) with light/dark cycles of 12 hours each and were allowed free access to food (Purina chow) and water. Experimental protocols and procedures were approved by the Federal University of Sergipe Animal Care and Use Committee (no. 27/09).

Pharmacologic experiments. All nociception and antiinflammatory tests were carried out by the same observer, and experiments were conducted in a quiet room at constant temperature of $23^{\circ} \mathrm{C}$. Drugs were administered orally at a dose/volume of $0.1 \mathrm{~mL} / 10 \mathrm{~g}$.

Antinociceptive activity: acetic acid-induced writhing. This test was performed according to the methods of Koster et al. ${ }^{17}$ and Broadbear et al. ${ }^{18}$ Abdominal contractions were induced by intraperitoneal injection of a $0.9 \%$ solution of acetic acid $(10 \mathrm{~mL} / \mathrm{kg})$ in mice ( $n=6$ per group). The animals in different groups were treated with $\operatorname{AEMC}(100,200$, and $400 \mathrm{mg} / \mathrm{kg}$ orally), the reference drug (morphine, $3 \mathrm{mg} /$ $\mathrm{kg}$, or acetylsalicylic acid, $200 \mathrm{mg} / \mathrm{kg}$ ), and vehicle (saline)
60 minutes before the acetic acid administration. The number of muscular contractions was counted for 15 minute. after injection.

Anti-inflammatory activity: leukocyte migration to the peritoneal cavity. Leukocyte migration was induced by intraperitoneal injection of carrageenan $(1 \%, 0.25 \mathrm{~mL})$ into the peritoneal cavity of mice 60 minutes after administration of $\operatorname{AEMC~}(100,200$, and $400 \mathrm{mg} / \mathrm{kg}$ orally), dexamethasone ( $2 \mathrm{mg} / \mathrm{kg}$ subcutaneously), or vehicle by modification of the technique previously described by Matos et al. ${ }^{19}$ The animals ( $n=6$ per group) were anesthetized with sodium pentobarbital ( $50 \mathrm{mg} / \mathrm{kg}$ intraperitoneally) and were euthanized by cervical dislocation 4 hours after carrageenan injection. Shortly after, saline containing EDTA $(1 \mathrm{mM}, 3 \mathrm{~mL})$ was injected intraperitoneally. Immediately a brief massage was done for further fluid collection; the fluid was centrifuged $(1000 \times g$, $5 \mathrm{~min}$ ) at room temperature. The supernatant was disposed and the precipitate was resuspended in saline. An aliquot of $10 \mu \mathrm{L}$ from this suspension was dissolved in $200 \mu \mathrm{L}$ of Turk solution, and the total cells were counted in a Neubauer chamber under optic microscopy. The results were expressed as the number of neutrophils $/ \mathrm{mL}$. The percentage of the leukocyte inhibition $=(1-T / C) \times 100$, where $T$ represents the treated groups' leukocyte counts and $C$ represents the control group's leukocyte counts.

\section{Statistical analysis}

The data were evaluated by 1-way analysis of variance followed by the Tukey test. The results are expressed as the means \pm standard error to show variation in groups. Data were analyzed by using Prism software, version 5.0 (GraphPad, La Jolla, CA, USA), and differences were considered significant when the $P$ value was less than .05 .

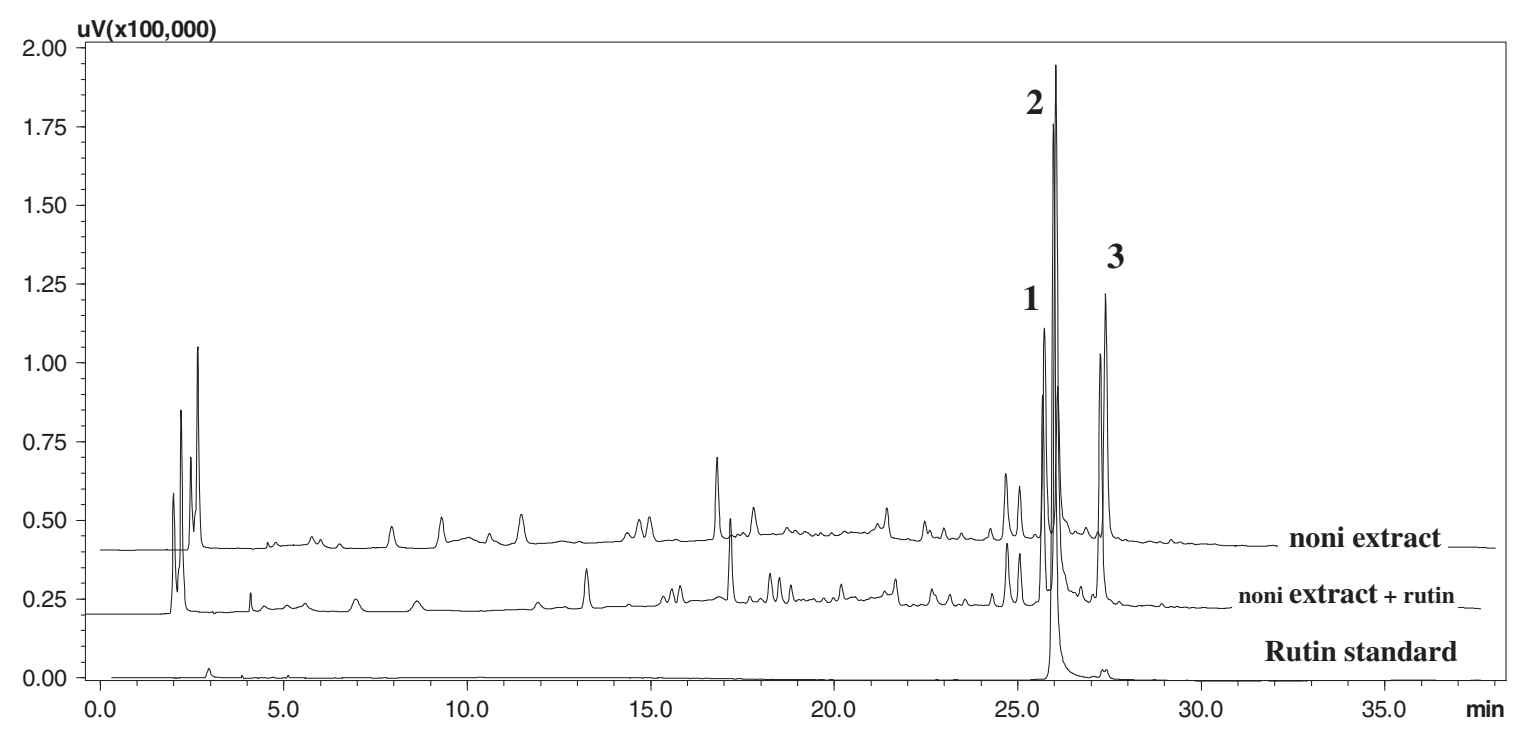

FIG. 1. High-performance liquid chromatograms at $254 \mathrm{~nm}$ of aqueous extract from Morinda citrifolia leaves and spiked with rutin. Kaempferol glycosides (peaks 1 and 3) and rutin (peak 2). 


\section{RESULTS AND DISCUSSION}

The AEMC was chemically analyzed (qualitative method). The phytochemical screening of AEMC showed the presence of alkaloids, coumarins, flavonoids, tannins, saponins, steroids, and triterpenoids. Total phenolic content of the extract was $196.8 \mathrm{mg}$ of phenolic equivalents (gallic acid) per gram of extract.

Qualitative analysis of AEMC was also performed by HPLC. Figure 1 shows the chromatographic profiles of AEMC and standards; good separation and resolution of peaks are visible. The phenolic compounds were characterized by retention times relative to external standards, peak spiking, and comparison of their ultraviolet spectra with the literature. HPLC-DAD analysis of the aqueous extract from leaves of noni revealed the presence of 3 major compounds (peaks 1-3), all showing ultraviolet spectra typical of flavonols. ${ }^{20}$ The flavonols identified in noni are derivatives of quercetin and kaempferol. ${ }^{21,22}$ According to the results, flavonoids are present in the AEMC analyzed by HPLC-DAD, and, on the basis of the use of commercial standards, peak 2 was identified as quercetin-3-O-rutinoside (rutin). According to the published data on the ultraviolet spectra (Fig. 2) and the elution sequence in HPLC-DAD, peaks 1-3 were suggested as kaempferol glycosides. ${ }^{23} \mathrm{Ac}$ cording to Deng et al., ${ }^{23}$ flavonol glycosides, mainly rutin, are the major compounds in noni leaves.

It has been proposed that phenolic compounds are antioxidants and anti-inflammatory agents. Furthermore, much attention has been given to the relationship between the antioxidant and anti-inflammatory properties of phenolic compounds in vitro and in vivo. ${ }^{24}$ Another anti-inflammatory property of phenolic compounds (e.g., flavonoids) is their ability to inhibit neutrophil degranulation. ${ }^{25}$ Indeed, studies have shown that certain flavonoids downregulate nitric oxide production in response to inflammatory stimuli. ${ }^{26}$

In addition, specific flavonoids are known to chelate iron, thereby removing a causal factor for the development of free radicals. Direct inhibition of lipid peroxidation is another protective measure. Selected flavonoids can reduce system complement activation, thereby decreasing the adhesion of inflammatory cells to the endothelium and in general resulting in a diminished inflammatory response. $^{25}$

\section{Thiobarbituric acid test}

Lipid peroxidation has been defined as the biological damage caused by free radicals that are formed under oxidative stress. ${ }^{27}$ Several plant extracts have been shown to inhibit lipid peroxidation, as measured by TBARS results. The lipids in membrane are continuously subjected to oxidant challenges. Oxidant-induced abstraction of a hydrogen atom from an unsaturated fatty-acid chain of membrane lipids initiates the process of lipid peroxidation, which propagates as a chain reaction. In the process, cyclic peroxides, lipid peroxides, and cyclic end peroxides are generated, which ultimately are fragmented into aldehydes such as malondialdehyde. ${ }^{28}$
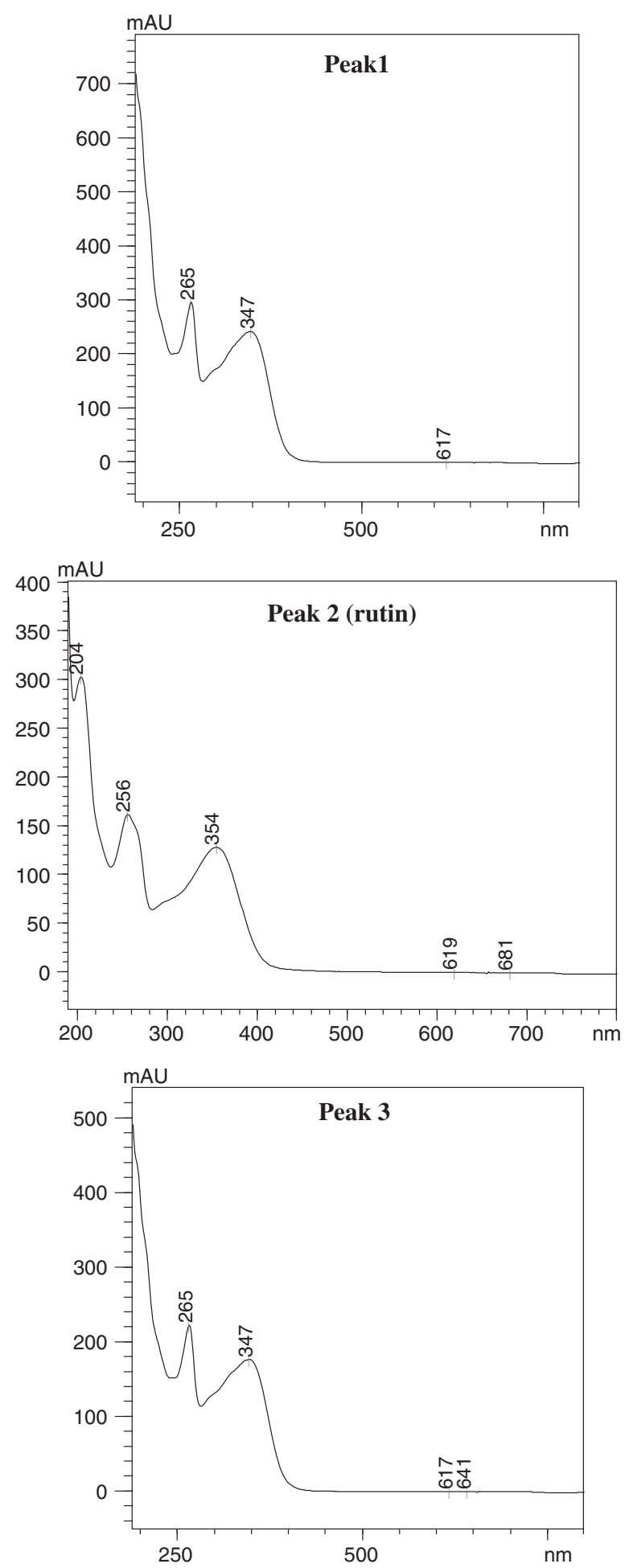

FIG. 2. Photodiode array ultraviolet spectra of flavonol glycosides (peaks 1-3) of aqueous extract from Morinda citrifolia leaves. AU, arbitrary units.

AEMC (all doses) inhibited the amount of TBARS generated by AAPH (Fig. 3), indicating a protective effect against lipid peroxidation. This result suggests that the AEMC may exert antioxidant protection on biomolecules such as phospholipids, triacylglycerols, and polyunsaturated 


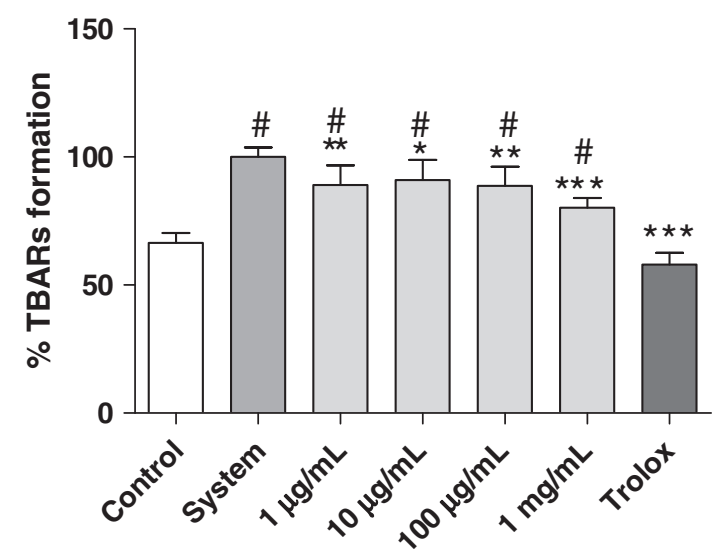

FIG. 3. Ability of different concentrations of aqueous extract from Morinda citrifolia leaves to prevent thiobarbituric acid reactive species formation was analyzed. Values represent mean \pm standard error; experiments were performed in triplicate. $* P<.05, * * P<.01$, $* * * P<.001$ versus system. ${ }^{\#} P<.05$ versus Trolox (analysis of variance followed by Tukey test). TBARS, thiobarbituric acid reactive species.

fatty acids in vivo, which are lipids essential to cellular membrane function and paracrine signaling.

\section{Hydroxyl radical-scavenging assay}

The hydroxyl radical is an extremely reactive species formed in biological systems and has been implicated as a highly damaging species in free radical pathology. This radical has the capacity to join nucleotides in DNA and cause strand breakage, which contributes to carcinogenesis, mutagenesis, and cytotoxicity. ${ }^{11,29,30}$ The hydroxyl radicalscavenging capacity of an extract is directly related to its antioxidant activity. The highly reactive hydroxyl radicals can cause oxidative damage to DNA, lipids, and proteins. ${ }^{11}$ We observed that the AEMC reduced deoxyribose oxidative damage at all concentrations (Fig. 4). The extract was highly effective in inhibiting hydroxyl damage. All doses tested $(1,10$, and $100 \mu \mathrm{g} / \mathrm{mL}$ and $1 \mathrm{mg} / \mathrm{mL})$ exhibited a

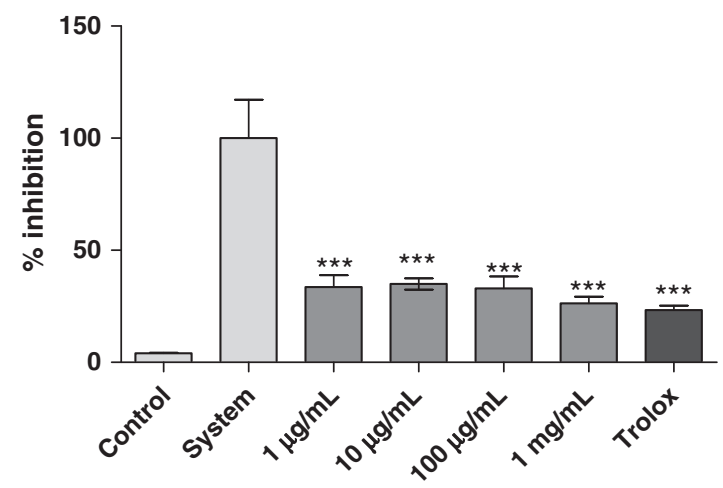

FIG. 4. Hydroxyl radical-scavenging activity of aqueous extract from Morinda citrifolia leaves. Values represent mean \pm standard error; experiments were performed in triplicate. $* * * P<.001$ versus system (analysis of variance followed by Tukey test). significant $(P<.05)$ antioxidant activity, which was similar to Trolox ${ }^{\circledR}$ (Hoffman-LaRoche, Basel, Switzerland), a synthetic analogue of $\alpha$-tocopherol used as an antioxidant standard.

\section{Nitric oxide-scavenging assay}

Nitric oxide plays an important role in various types of inflammatory processes. It is produced by macrophages in the course of the inflammatory response. It is mutagenic and can interfere with DNA repair processes. ${ }^{31}$ In this study, the AEMC was checked for its inhibitory effect on nitric oxide production.

To determine the ability of AEMC as a reactive nitrogen species scavenger, we evaluated the nitric oxide-scavenging activity by incubating AEMC with sodium nitroprusside, a chemical inducer of nitric oxide production. Figure 5 shows that AEMC at doses of $100 \mu \mathrm{g} / \mathrm{mL}$ and $1 \mathrm{mg} / \mathrm{mL}$ significantly decreased nitric oxide production (11\% and 19\% of inhibition, respectively).

\section{Microdilution assays}

The AEMC showed no activity against the gram-positive and gram-negative bacteria tested except for Aeromonas hydrophila (Table 1). This finding could be related to the absence of anthraquinones in the extract because ChanBlanco et al. ${ }^{2}$ and Wang et al. ${ }^{1}$ demonstrated the antimicrobial activity of this compound.

\section{Acetic acid-induced writhing}

Acetic acid-induced writhing is a visceral pain model widely used to evaluate peripheral antinociceptive activity. Although this test is a nonspecific model (e.g., anticholinergic, tricyclic antidepressants, and antihistaminic and other agents

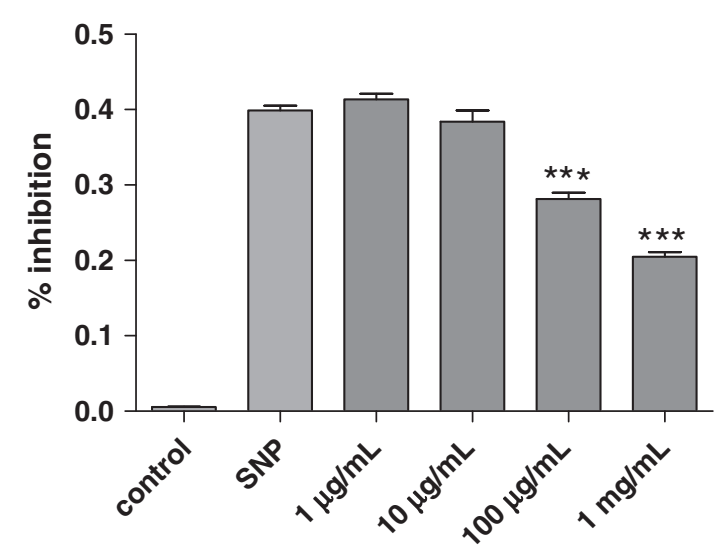

FIG. 5. Nitric oxide radical-scavenging activity of aqueous extract from Morinda citrifolia leaves. Values represent mean \pm standard error; experiments were performed in triplicate. Control group refers to Griess absorbance in the absence of nitric oxide inductor, and SNP group is the nitric oxide inductor sodium nitroprusside $(5 \mathrm{mM})$. Different concentrations of the extracts were incubated along with sodium nitroprusside. $* * * P<.001$ versus sodium nitroprusside (analysis of variance followed by Tukey test). 
Table 1. Inhibitory Concentration of Aqueous Extract From Morinda CITRIFOLIA LEAVES AgAinst BACTERIA

\begin{tabular}{lccc}
\hline Microorganisms & $\begin{array}{c}\text { ATTC } \\
\text { No. }\end{array}$ & $\begin{array}{c}\text { Gram stain } \\
\text { result }\end{array}$ & $\begin{array}{c}\text { MIC } \\
(\mathrm{mg} / \mathrm{mL})\end{array}$ \\
\hline Salmonella typhi & 8739 & Gram-negative & $>10$ \\
Escherichia coli & 9120 & Gram-negative & 10 \\
Klebsiella pneumoniae & 9341 & Gram-negative & 5 \\
Proteus mirabilis & 10031 & Gram-negative & 5 \\
Pseudomonas aeruginosa & 25923 & Gram-negative & 1.25 \\
Aeromonas hydrophila & 29212 & Gram-negative & 0.625 \\
Micrococcus species & 14153 & Gram-positive & 2.5 \\
Staphylococcus aureus & 27853 & Gram-positive & 2.5 \\
Enterococcus faecalis & 7966 & Gram-positive & 5 \\
\hline
\end{tabular}

ATCC, American Type Culture Collection.

show activity in this test), it is widely used for analgesic screening and involves local peritoneal receptors (cholinergic and histaminic receptors) and the mediators acetylcholine and histamine. $^{24,32,33}$ These peripheral nociceptive fibers are sensitive to both narcotic analgesic (morphine) and nonsteroid anti-inflammatory drugs, such as aspirin. ${ }^{34}$

The results depicted in Figure 6 showed that the AEMC $(400 \mathrm{mg} / \mathrm{kg})$, given 60 minutes before, produced a significant $(P<.001)$ reduction in abdominal constrictions induced by acetic acid in mice. This result suggests that AEMC may also help inhibit prostaglandin synthesis because nociceptive mechanisms involve the processing or release of arachidonic acid metabolites via cyclooxygenase and prostaglandin biosynthesis. ${ }^{35}$ Because cyclooxygenase may be activated by nitric oxide, ${ }^{36,37}$ a possible link between the antioxidant and antinociceptive activities exerted by AEMC might be its nitric oxide-scavenging ability.

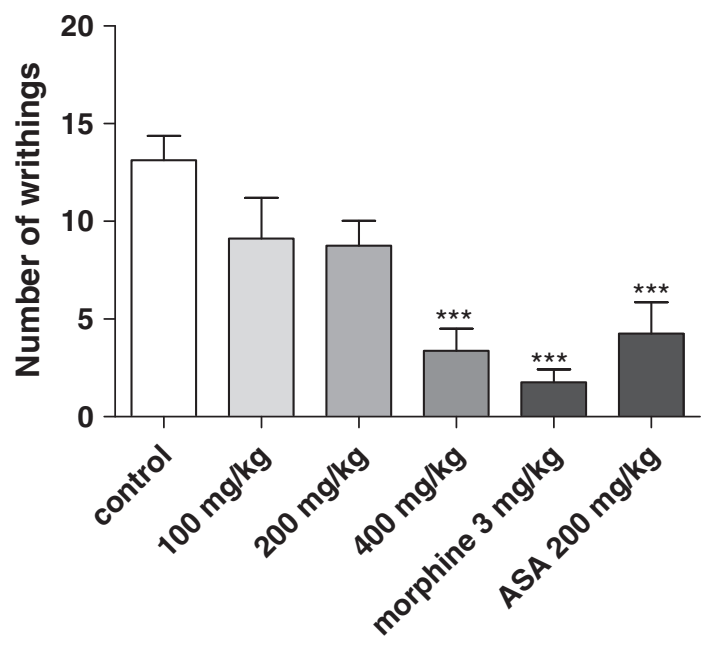

FIG. 6. Effects of aqueous extract from Morinda citrifolia leaves on the acetic acid-induced writhing test. Vehicle (control), aqueous extract $(100,200$, and $400 \mathrm{mg} / \mathrm{kg})$, morphine, or acetylsalicylic acid were administered orally 0.5 hour before acetic acid injection. Each column represents mean \pm standard error $(n=6)$. $* * * P<.001$ versus control (analysis of variance followed by Tukey test). ASA, acetylsalicylic acid.

\section{Leukocyte migration to the peritoneal cavity}

To determine the probable anti-inflammatory activity of AEMC, the peritonitis-induced-by-carrageenan test was performed in mice. The carrageenan is known to be an excellent acute inflammatory agent in which fluid extravasation, leukocyte migration, and biochemical parameters in the exudate can be easily detected. Injection of carrageenan on the dorsal surface of mice initiates an inflammatory process. ${ }^{38}$

Because chemotaxis is important in the initiation and exacerbation of an inflammatory response, our results confirm some of the signs of inflammation, such as a decrease in the leukocyte count, observed in the blood of mice that were treated by AEMC ingestion.

Figure 7 shows the inhibitory effect of AEMC (200 and $400 \mathrm{mg} / \mathrm{kg}$ ) and dexamethasone ( $2 \mathrm{mg} / \mathrm{kg}$ subcutaneously) on carrageenan-induced responses. There was significantly $(P<.05)$ decreased leukocyte migration (predominantly neutrophil migration).

The results of this test showed that the AEMC significantly reduced the number of recruited cells. These findings therefore suggest that AEMC contains active anti-inflammatory agents.

The role of nitric oxide in physiologic and pathologic processes such as inflammation is well-known. It is reported that nitric oxide itself expresses chemotactic activity. ${ }^{24,39} \mathrm{In}$ addition, reactive oxygen species and reactive nitrogen species have also been reported to act as proinflammatory signals in vivo by stimulating the activation of tumor necrosis factor- $\alpha$, interleukin- $1 \beta$, and interleukin- 6 genes through the activation of the redox-sensitive transcription factor nuclear factor- $\kappa \mathrm{B} .{ }^{40}$ The antinociception and antiinflammatory effects induced by AEMC could thus also be a

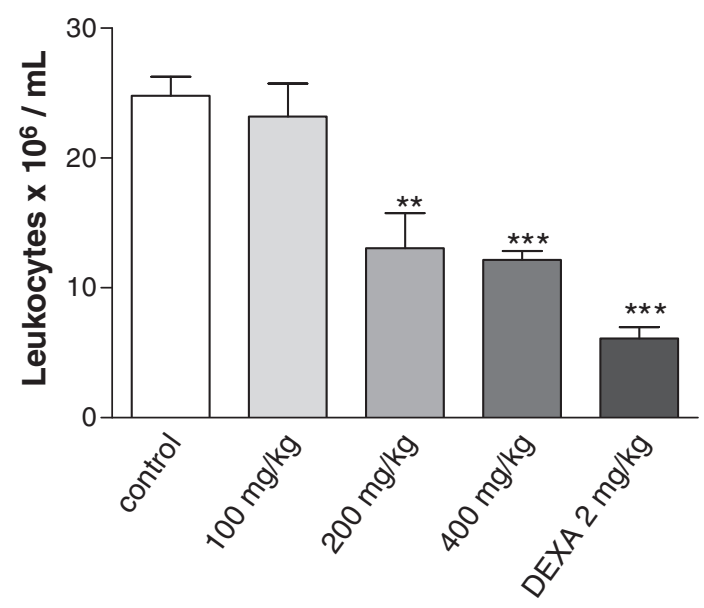

FIG. 7. Effect of aqueous extract from Morinda citrifolia leaves $(100,200$, and $400 \mathrm{mg} / \mathrm{kg})$ on leukocyte migration into the peritoneal cavity induced by carrageenan. Groups of mice were pretreated with vehicle or dexamethasone $(2 \mathrm{mg} / \mathrm{kg})$. Each value represents the mean \pm standard error. $* * * P<.001$ and $* * P<0.01$ versus control group (analysis of variance followed by Tukey test) $(n=6)$. DEXA, dexamethasone. 
consequence of its antioxidant ability, which may prevent the free radical-induced nuclear factor $-\kappa \mathrm{B}$ activation and consequent proinflammatory cytokine production, a cycle that perpetuates inflammatory processes. ${ }^{41}$

\section{CONCLUSION}

Our results indicate that AEMC has mild antibacterial activity and significant antioxidant, antinociceptive, and anti-inflammatory effects, which provide pharmacologic evidence for folk uses of $M$. citrifolia Linn. Other studies have reported that the $M$. citrifolia leaf extract contains polyphenols. Therefore, the biological effects of the leaf extract may depend on its phenolic components. However, the dosage used appears to be high, and additional studies are necessary to evaluate the potential toxicity of the extract and its possible safe and therapeutically efficient dosage in humans. In addition, further studies, isolation, and characterization will be undertaken to correlate the pharmacologic activities with the chemical constituents.

\section{ACKNOWLEDGMENTS}

We thank Mr. Osvaldo Andrade Santos for technical support. We also thank Dr. Valeria Regina de Souza Moraes (Department of Chemistry, Federal University of Sergipe, Brazil) for kindly giving a sample of rutin. This work was supported by Fundação de Amparo à Pesquisa do Estado de Sergipe (FAPITEC-SE) and Conselho Nacional de Desenvolvimento Científico e Tecnológico (CNPq) of Brazil.

\section{AUTHOR DISCLOSURE STATEMENT}

The authors report no conflicts of interest. The authors alone are responsible for the content and writing of this paper.

\section{REFERENCES}

1. Wang MY, West BJ, Jensen CJ, et al:: Morinda citrifolia (Noni): a literature review and recent advances in Noni research. Acta Pharmacol Sinica 2002;23:1127-1141.

2. Chan-Blanco Y, Vaillant F, Perez AM, et al.: The noni fruit (Morinda citrifolia L.): a review of agricultural research, nutritional and therapeutic properties. J Food Comp Anal 2006;19: 645-654.

3. Elkins RMH: Hawaiian Noni (Morinda citrifolia). Prize Herb of Hawaii and the South Pacific Noni. Pleasant Grove, Utah, Woodland Publishing, 1998.

4. West BJ, Jensen CJ, Westendorf J, White LD: Safety tests and antinutrient analyses of noni (Morinda citrifolia L.) leaf. $J$ Sci Food Agric 2007;87:2583-2588.

5. Wang MY, Su C: Cancer preventive effect of Morinda citrifolia (Noni). Ann N Y Acad Sci 2001;952:161-168.

6. Matos FJA: Introdução a Fitoquímica Experimental, 2nd ed. Edições UFC, Fortaleza, 1997.

7. Singleton VL, Orthofer R, Lamuela-Raventos RM: Analysis of total phenols and other oxidation substrates and antioxidants by means of Folin-Ciocalteu Reagent. Meth Enzymol 1999;299:152-178.
8. Draper HH, Hadley M: Malondialdehyde determination as index of lipid peroxidation. Meth Enzymol 1990;186:421.

9. Ottolenghi A: Interaction of ascorbic acid and mitochondrial lipids. Arch Biochem Biophys 1959;79:355-358 .

10. Kikuzaki H, Nakatani N: Antioxidant effects of some ginger constituents. J Food Sci 1993;58:1407-1410.

11. Shukla S, Mehta A, Bajpai V, Shukla S: In vitro antioxidant activity and total phenolic content of ethanolic leaf extract of Stevia rebaudiana Bert. Food Chem Toxicol 2009;47:2338-2343.

12. Payá M, Halliwell B, Hoult JRS: Interactions of a series of coumarins with reactive oxygen species. Scavenging of superoxide, hypochlorous acid and hydroxyl radicals. Biochem Pharmacol 1994;44:205-214.

13. National Committee for Clinical Laboratory Standards (NCCLS): Methods for Dilution, Antimicrobial Susceptibility Tests for Bacteria That Grow Aerobically. 5th ed. Volume 17. Approved standards-M7-A4. NCCLS document M7-A4. Wayne, Pennsylvania, National Committee for Clinical Laboratory Standards, 2003.

14. Dall' Agnol R, Ferraz A, Bernardi AP, et al.: Antimicrobial activity of some Hypericum species. Phytomedicine 2003;10:511-516.

15. Fabry W, Okemo PO, Ansorg R: Antibacterial activity of East African medicinal plants. J Ethnopharmacol 1998;60:79-84.

16. Tanaka JCA, Silva CC, Dias Filho BD, et al.: Constituintes químicos de Luehea divaricata Mart. (Tiliaceae). Quim Nova 2005;5:834-837.

17. Koster R, Anderson M, Beer EJ: Acetic acid for analgesic screening. Fed Proceed 1959;18:412-416.

18. Broadbear JH, Negus SS, Butelman ER, Costa BR, Woods JH: Differential effects of systemically administered nor-binaltorphimine (nor-BNI) on k-opioid agonists in mouse writhing assay. Psychopharmacology (Berl) 1994;15:311-319.

19. Matos LG, Santos LDAR, Vilela CF, et al.: Atividades analgésica e/ou antiinflamatória da fração aquosa do extrato etanólico das folhas da Spiranthera odoratissima A. St. Hillaire (manacá). Rev Bras Farmacogn 2003;13(Suppl):15-16.

20. Ducrey B, Wolfender JL, Marston A, Hostettmann K: Analysis of flavonol glycosides of thirteen Epilobium species (Onagraceae) by LC-UV and thermospray LC-MS. Phytochemistry 1995;38:129-137.

21. Sang S, Cheng X, Zhu N, et al.: Flavanol glycosides and novel iridoid glycoside from the leaves of Morinda citrifolia. J Agric Food Chem 2001; 49:4478-4481.

22. Takashima J, Ikeda Y, Komiyama K, et al.: New constituents from leaves of Morinda citrifolia. Chem Pharm Bull 2007;55:343-345.

23. Deng S, West BJ, Jensen CJ: Simultaneous characterisation and quantitation of flavonol glycosides and aglycones in noni leaves using a validated HPLC-UV/MS method. Food Chem 2008;111: 526-529.

24. Queiroz AC, Lira DP, Dias TLMF, et al.: The antinociceptive and anti-inflammatory activities of Piptadenia stipulacea Benth. (Fabaceae). J Ethnopharmacol 2010;128:377-383.

25. Nijveldt RJ, Van-Nood E, Van-Hoorn DEC, et al.: Flavonoids: a review of probable mechanisms of action and potential applications. Am J Clin Nutr 2001;74:418-425.

26. Hämäläinen M, Nieminen R, Vuorela P, Heinonem M, Moilanen E: Anti-Inflammatory effects of flavonoids: genistein, kaempferol, quercetin, and daidzein inhibit stat-1 and nf-kappab activations, whereas flavone, isorhamnetin, naringenin, and pelargonidin inhibit only nf-kappab activation along with their inhibitory effect on inos expression and no production in activated macrophages. Mediators Inflamm 2007;2007:45673. 
27. Zin ZM, Abdul-Hamid A, Osman A: Antioxidative activity of extracts from Mengkudu (Morinda citrifolia L.) root, fruit and leaf. Food Chem 2002;78:227-231.

28. Sreelatha S, Padma PR: Antioxidant activity and total phenolic content of Moringa oleifera leaves in two stages of maturity. Plant Foods Hum Nutr 2009;64:303-311.

29. Hochestein P, Atallah AS: The nature of oxidant and antioxidant systems in the inhibition of mutation and cancer. Mutat Res 1998;202:363-375.

30. Manian R, Anusuya N, Siddhuraju P, Manian S: The antioxidant activity and free radical scavenging potential of two different solvent extracts of Camellia sinensis (L.) O. Kuntz, Ficus bengalensis L. and Ficus racemosa L.. Food Chem 2008;107: 1000-1007.

31. Okoko T: Chromatographic characterisation, in vitro antioxidant and free radical scavenging activities of Garcinia kola seeds. Afr J Biotechnol 2009;8:7133-7137.

32. Verma PR, Joharapurkar AA, Chatpalliwar VA, Asnani AJ: Antinociceptive activity of alcoholic extract of Hemidesmus indicus R.Br. in mice. J Ethnopharmacol 2005;102:298-301.

33. Du J, Yu Y, Ke Y, et al.: Ligustilide attenuates pain behavior induced by acetic acid or formalin. J Ethnopharmacol 2007;112: 211-214.
34. Wibool R, Chutha S, Wantana R, Malinee W: Antinociceptive activity of the methanolic extract of Kaempferia galangal Linn. in experimental animals. J Ethnopharmacol 2008;118:225-230.

35. Le Bars D, Gozariu M, Cadden SW: Animal models of nociception. Pharmacol Rev 2001;53:597-652.

36. Salvemini D, Currie MG, Mollace V: Nitric oxide-mediated cyclooxygenase activation. J Clin Invest 1996;97:2562-2568.

37. Mollace V, Muscoli C, Masini E, Cuzzocrea S, Salvemini D: Modulation of prostaglandin biosynthesis by nitric oxide and nitric oxide donors. Pharmacol Rev 2005;57:217-252.

38. Yoo HJ, Kangb HJ, Junga HJ, et al:: Anti-inflammatory, antiangiogenic and anti-nociceptive activities of Saururus chinensis extract. J Ethnopharmacol 2008;120:282-286.

39. Adachi R, Matsui S, Kinoshita M, et al.: Nitric oxide induces chemotaxis of neutrophil-like HL-60 cells and translocation of cofilin to plasma membranes. Int J Immunopharmacol 2000;22: 855-864.

40. Beauparlant P, Hiscott J: Biological and biochemical inhibitors of the NF-kappa B/Rel proteins and cytokine synthesis. Cytokine Growth Factor Rev 1996;7:175-190.

41. Guimarães AG, Oliveira GF, Melo MS, et al.: Bioassay-guided evaluation of antioxidant and antinociceptive activities of carvacrol. Basic Clin Pharmacol Toxicol 2010;107:949-257. 